\title{
Características de vulnerabilidad social del infractor adulto y su relación con la comisión de delitos graves en el departamento de Rivas ${ }^{1}$
}

\author{
Characteristics of social vulnerability of the adult offender and its relation to the commission \\ of serious crimes in the department of Rivas
}

\author{
Marvin Ernesto, Mora Rosales ${ }^{2}$ \\ (iD https://orcid.org/0000-0001-6433-8180 \\ Universidad Politécnica de Nicaragua, Managua, Nicaragua
}

\section{Como referenciar este artículo:}

Mora., R., M., E. (2021). Características de vulnerabilidad social del infractor adulto y su relación con la comisión de delitos graves en el departamento de Rivas. Revista Ciencia Jurídica y Política, 94-125.

\section{RESUMEN}

El objetivo de este artículo es conocer mediante un análisis la situación de inseguridad de la ciudad de Rivas, el impacto de la criminalidad organizada y los factores ambientales que propiciaron el incremento delictivo, resaltando las características de vulnerabilidad social de los infractores de la ley y su relación con la comisión de delitos, las condiciones que facilitan o propician transformaciones de la conducta y las características socioculturales comunes en la comisión de delito y faltas; La información se extrajo de causas Judicializada en la ciudad de Rivas, por ser una zona fronteriza con altos índices de transculturización y alta actividad delictiva flotante. Los resultados indican que la mayoría de los adultos que quebrantaron la ley son varones y se perciben a sí mismos dentro de la categoría de infractores a pesar de mantener una alta frecuencia de conductas antisociales; se establecen perfiles de identificación para la población en relación con su percepción de anomia social, psicológica y alienación, se presentan perfiles adultos en alto riesgo de presentar un alto índice de conductas delictivas. Se concluye que la percepción de apoyo en el microambiente familiar y social es fundamental para la diferenciación de aquellos infractores con alta percepción de conductas antisociales y socio culturales.

Palabras Claves: Delito, derecho Penal, derecho procesal Penal, judicialización, rol Social

\begin{abstract}
The objective of this article is to know though an analysis the situation of insecurity in the city of Rivas, the impact of organized crime and the environmental factors that led to the increased crime, highlighting the characteristics of social vulnerability of offenders and their relationship to the commission of offenses, the conditions that facilitate or encourage changes in behavior and common sociocultural characteristics in the commission of crime and misconduct; the information was extracted from judicialized cases in the city of Rivas, because it is border area with high rates of transculturation and high floating criminal activity. The results indicate that most adults who broke the law are male and perceive themselves as offenders despite the high prevalence of anti-social behavior; identification profiles are established for the population in relation with the perception of social, psychological anomie and alienation, and adult profiles are presented at high risk of present a high index of criminal behavior. It is concluded that the perception of support in the family microenvironment and social, is fundamental for the differentiation of these offenders with high perception of antisocial and socio-cultural behaviors.
\end{abstract}

Key Word: Crime, criminal law, criminal procedural law, judicialization, social role.

Recibido: 23.04.21

Aceptado: 12.06.21

Este trabajo está licenciado bajo una licencia:

Creative Commons Atribución- No Comercial Internacional 4.0

\footnotetext{
${ }^{1}$ Artículo de revisión que aborda la vulnerabilidad social del infractor adulto y la comisión de delitos graves en Rivas, Nicaragua.

${ }^{2}$ Máster en Derecho Procesal por la Universidad Politécnica de Nicaragua, docente de la Escuela de Ciencias Jurídicas y Políticas RURRivas. Correo de contacto: moramer06@hotmail.com.
} 


\section{1.- INTRODUCCIÓN}

La inseguridad ciudadana en el departamento de Rivas constantemente ha ido en crecimiento producto de factores ambientales que propiciaron el incremento delictivo y de la criminalidad organizada, por lo que se hizo necesario resaltar las características de vulnerabilidad social de los infractores de la ley y su relación con la comisión de delitos, con el único fin de entender los conflictos de naturaleza Jurídico-social con la aplicación de las leyes, los derechos de la víctima y la convivencia social armónica de los ciudadanos, tomando como precepto la aplicación de las penas y medidas de seguridad acorde con los principios penales y humanos de los acusados en el departamento de Rivas.

Bajo estas premisas, pretendo establecer que la judicialización de los hechos cometidos por los acusados en el departamento de Rivas en los últimos años, propiciaron transformaciones jurídicas-sociales en la prevención del delito, adecuación y judicialización de los procesos, la sanción y los mecanismos de reinserción social, todo amparado en el dilema de cumplimiento del debido Proceso, observancia de los principios rectores, dignidad humana como asistencia jurídica efectiva del acusado.

Con las transformaciones existente en el sistema jurídico penal denominado reformas, se ha logrado determinar con certeza las acciones que propician delitos, pero en su conjunto no han sido suficientes para determinar las condiciones sociológicas-jurídicas que lo generan, ni la motivación del accionar delictivo, por lo que se debe fomentar la prevención de delito dentro de un fondo situacional complejo de características multidimensionales, siendo necesario entonces profundizar en la situación social y económica de los rivenses para ayudarnos a identificar algunos de los factores que en este municipio conllevan a la comisión de delitos.

En los últimos años, los administradores de justicia en raras ocasiones toman en consideración las características (cualidades inherentes) de origen congénito o adquirido de los procesados, que hacen que un hecho delictivo sea único y cometido por persona con una misma individualidad; por lo que al momento de judicializar la causa se violenta los derechos de los acusados con una mal denominada política de estado no instituida. Cuando existen inobservancias en la aplicación de la ley por parte del judicial en algunos tipos penales que 
se aplican bajo el criterio de políticas de estados. Lo anterior se sustenta a través de Llobet Rodríguez (2002) que refiere "que se trata en definitiva de un principio que está relacionado también con el Estado de Derecho, en cuanto se garantiza la seguridad jurídica de los habitantes del Estado, de modo que no pueden ser condenados sino es conforme a una serie de normas que garanticen la presunción de inocencia y el derecho de defensa, lo mismo que la imparcialidad del Juzgador”.

La judicialización de un proceso penal nicaragüense contemplado en la ley 406 no cuenta con la identificación de factores sociales que incrementan la criminalidad al momento de la comisión del hecho; causando un limitada defensa material y técnica en los procesos, por lo que se deriva un cambio radical en los supuestos de las políticas dirigidas a los estudios sobre vulnerabilidad social que se encuentran en un momento de auge dado su carácter multidisciplinar, lo que ha propiciado que se identifiquen e investiguen grupos vulnerables desde diferentes perspectivas metodológicas, y a distintas escalas, apareciendo así numerosas líneas de investigación que se abordan desde este enfoque (Código Procesal Penal de Nicaragua, 2001). A pesar de ello, su progreso no ha estado exento de críticas sobre el verdadero avance de la vulnerabilidad social, convertido en uno de los temas más controvertidos de la agenda de las políticas públicas en América Latina (Ramos Ojeda \& Busso, 2001).

\section{Base teórica relacionada al delito y sus incidencias en el departamento de Rivas.}

La criminalidad en el departamento de Rivas que se registró en años anteriores según estudios de las estadísticas de la Policía nacional publicada cada año: un índice de incidencia de 587 delitos por cada 10 mil habitantes (la cifra más alta de incidencia delictiva municipal en todo el país), por lo que consideramos necesario determinar cuáles fueron los factores que propiciaron el incremento delictivo y de mayores niveles de inseguridad en esa ciudad (Policía Nacional, 2018).

Se hace importante aclarar, que cuando se habla de inseguridad ciudadana o incidencia de la criminalidad, en Nicaragua no sólo se puede contar con las cifras de la Policía Nacional, debido que el acceso a la información es nulo, ante lo cual debe crearse un sistema estadístico integrado en la característica principal de los hechos delictivos comunes de 
nuestro tiempo, y el aporte del sistema Nicarao que es proporcionado por el poder Judicial como una base de datos de causas judicializadas en el departamento y que registra toda las acciones y actos judiciales sobre cada causa.

Es importante resaltar que los factores considerados para el aumento creciente de la criminalidad nació en el enfoque sociológico de la criminología, el cual se concentraba en explicar sobre algunas condiciones sociales o económicas como la pobreza, eran detonantes de la conducta delictiva y que, aunado con los factores biológicos y psicológicos, hacían que los individuos quebrantaran la ley con más frecuencia, sobre todo cuando las costumbres autóctonas se mezclan con la transculturización de los turistas que visitaban el departamento (Romero, 2017).

Si bien es cierto que el desarrollo de un pueblo se considera lo más relevante para las condiciones de vida de sus miembros, el mismo trae consecuencias transformadoras de las conductas antisociales y por ende también el desarrollo de la criminalidad habitual y la criminalidad organizada, es decir los ingresos constituyen el principal factor de riesgo en las sociedades emergentes, no solo por la necesidad de administrar las nuevas riquezas, sino porque los individuos no son capaces de administrar las contingencias sociales de manera individual por muy diferentes motivos.

Se sostiene que en Nicaragua existe una estructura jurídica penal que sirve de barrera a la nueva delincuencia, pero la comisión de actos delictivos se ajusta rápidamente a los cambios por ser Rivas un departamento fronterizo de países con delincuencias bien estructuradas y con recursos ilimitados. En este sentido, la comisión de delito en este departamento son crimen organizado, asesinato, violación, tráfico de estupefaciente en sus distintas modalidades, lavado de dinero y activos y los robos en sus distintas modalidades. Por lo que, "es indudable que la discusión sobre la posibilidad de un control penal más humano es uno de los componentes más importantes de la situación actual del pensamiento criminológico contemporáneo” Chirino Sánchez en Llobet Rodríguez (2002). 
Mora., R., M., E.

\section{2.- DESARROLLO}

\section{Necesidad de la valoración moral en el delito}

Pesa sobre el conocimiento del derecho una responsabilidad que el mismo tiempo ha forjado mediante la cultura de los pueblos, por lo que las leyes y la justicia desmesuradamente busca una conservación de las libertades de los pueblos regulando las cuotas de poder, para mantener la balanza de la aplicación de las leyes y sus ciudadanos como mecanismo perfecto del estado de derecho.

En Nicaragua, desde su formación histórica como nación, nació con un espíritu elevado y vigoroso forjado de la humillación y el desdén de los conquistadores, encareciendo la voluntad pacifista como fruto prohibido de una sociedad sometida por el poder y sus gobernantes, que en lo natural no es ninguna rareza que nuestro pensamiento y accionar sea encaminado al mal, al derramamiento de sangre, al anhelo de la libertad.

El cronista Martínez Peláez (2020) escribió "la espada de los conquistadores no sea había bañado en sangre vanamente, sino con el fin de poner a las sociedades indígenas bajo el dominio de los nuevos amos", (los españoles). Debemos entender que los indígenas convivieron bajo la avasalladora conquista de estos, además fueron oprimidos por los criollos quienes se apropiaron de las costumbres que les beneficiaban y erradicaron aquellas que consideraban contrarias a sus pensamientos religiosos.

Este cronista se refiere a la sociedad nicaragüense como indígenas del dominio de nuevos amos, pueblo que su benevolencia lo inclinó a vivir bajo un principio agresivo y hostil, a una pasión grosera a perjudicar al otro y de servirse a sí mismo, llevando sentimiento de animosidad, formando una sociedad de hombre que se dividen por política, ideología, por religión, por género y por facciones de clase (Martínez Peláez, 2020).

Desde la formación del mundo hasta nuestros días, cuando el hombre comenzó a vivir en sociedad el hombre ha reclamado para sí su derecho absoluto sobre las cosas y los bienes, estableciendo sobre ellas la palabra mías y en el periodo de esclavitud sobre los seres humanos haciéndolos esclavos. Sin embargo, la igualdad natural fue antes que la igualdad de 
las leyes, porque sin determinación de derecho, ¿cómo puede saber el hombre que es lo que le pertenece, ¿cuáles son sus derechos y cuáles son sus deberes?

El hombre no es sociable por naturaleza, sino por necesidad, busca la guerra como medio pacificador, el gran filósofo griego Aristóteles expresó que "sólo un Dios o una bestia podían vivir alejados de la sociedad". La bestia, porque no necesita del hombre para vivir, y si el hombre viviera aislado, "sólo respiraría guerra, porque sería incapaz de unirse con nadie como sucede a las aves de rapiña”. Dios, porque siendo omnipotente y eterno, no requiere la ayuda del hombre, pero éste, "es un ser naturalmente sociable, y el que vive fuera de la sociedad por organización y no por efecto del azar, es, ciertamente, o un ser degradado, o un ser superior a la especie humana... es un bruto o un dios".

Así que, no se debe de negar, que existe una gran diferencia entre el derecho natural (instinto) y la ley natural basada en la necesidad humana, porque el derecho natural es la libertad que tiene todo ser humano racional de usar su poder como él entienda mejor para conservarse en ausencia de protección de quien lo gobierna; y la ley natural es la regla por la cual uno se opone a todo lo que le pueda perjudicar, partiendo del estado racional de la necesidad de subsistencia.

Cuando nos amparamos que el hombre viene de creación divina, por tal razón nuestra libertad es absoluta y no debemos ser gobernados, la misma Escritura Bíblica nos enseñan que la libertad no es absoluta; el apóstol san Pablo en Gálatas 5: 13 dice: "porque vosotros hermanos a libertad fuiste llamado; solamente que no uséis la libertad como ocasión para la carne, sino servíos por amor los unos a los otros" (Santa Biblia, 1960). Lo antes planteado nos debe hacer entender que como seres humanos no debemos responder a nuestros impulsos, porque hacerlo es violentar el derecho de los demás, y por lo tanto el orden institucional cuyo fin es restaurar la paz social.

\section{Aspecto Educacional del individuo (antijuridicidad).}

Cuando se enseña que el Derecho es el conjunto de normas que regulan la conducta del hombre dentro de la sociedad, también se nos dice que el actuar de los seres humanos, aunque contrario al orden constitucional también puede justificarse, convirtiendo un acto de 
antijuridicidad en acto jurídico legítimo, por el solo hecho de preservar un interés jurídico superior (derecho a la vida) para él o para cualquier persona (legítima defensa). Sin embargo, el actuar volitivo de la acción del actor debe reunir presupuestos determinados en la ley, como presupuestos del orden social impuesto por el poder público que gobierna a la sociedad.

Cuando nos referirnos al derecho natural del hombre dentro de la sociedad, debemos pensar que es un pensamiento épico, porque el hombre al vivir en sociedad, tiene que convertirse en ciudadano, y por lo tanto debe permitirse ser gobernado, su accionar tiene límites, por leyes creadas por algún órgano del gobierno que lo rige (Asamblea Nacional), tal razón lleva a determinar que no puede el hombre ser libre sin que el gobierno que lo rige determina los límites de sus acciones como ciudadanos en cuanto a sus deberes y derechos, y del límite dónde empieza o termina un derecho y dónde termina o empieza el del otro, es decir, determinar el inicio del derecho que una persona ejerce sobre las cosas y dónde se extingue este derecho; donde empieza el derechos de los demás y donde se pierde el derechos de los demás y, en su defecto, cómo aceptar formas de traslación del derecho propio hacia los demás y qué normas de conductas pueden regularlos para obligar su cumplimiento.

Podemos establecer que el hombre no pierde su derecho dentro de la sociedad, porque se sabe por los estudiosos del derechos, que el derecho nace con el ser humano y es un derecho intrínseco e innato, sin embargo, el pertenecer a la sociedad hace que el hombre se transforme en ciudadano, deposite su confianza en un gobernante, y por lo tanto, este creara leyes para mejoras de la gobernabilidad, conllevando a determinar que el hombre no es sociable por naturaleza sino por accidente o por necesidad de asociarse, por ejemplo, cuando un ciudadano viaja, lo primero que hace es resguardar su casa para evitar que durante su ausencia sea objeto de robo; esto se convierte en una acusación de la naturaleza humana (inseguridad) en contra de la sociedad organizada (estado); es decir el hombre por naturaleza propia busca su propia seguridad, porque desconoce o no confía en la capacidad del estado para proteger su patrimonio, y su amparo está en la fuerza o la astucia que motiva su virtud de seguridad.

Cuando el hombre se sujeta a la organización social, este demanda que los que la forman tengan la suficiente seguridad de poder interactuar sin sentirse reprimido por quien 
lo gobierna, y a su vez sentirse con la capacidad suficiente de poder disponer de su vida y acciones libremente con las limitaciones previamente establecida por el orden institucional, para evitar que los agentes del orden institucional no tengan la capacidad de protegerlos o que sus acciones contraríen a la ley, porque si tienes poder para gobernar a los ciudadanos también lo tienes para reprimirlos y restringir sus derecho.

El hombre en su naturaleza propia resiste a todo lo que considera que limita su libertad de actuar, pensar y decidir, pero esto no puede ser motivo para que viva con en el temor que para alcanzar la libertad debe matarse entre sí; los derechos del hombre son consagrados en el consentimiento y sujeción del desprendimiento del derecho absoluto, es por tal razón que nadie puede acusarse por sí mismo, sino es el orden público el que se encarga; de modo que, por la fuerza no se puede imponer ni regular al hombre dentro de la sociedad salvo que su consentimiento a si lo permita o la ley lo disponga como acto de prevención social.

Podemos ver que en la actualidad cada día es más difícil que el hombre se someta a regulaciones, si vemos esto ha conllevado a que las naciones centroamericanas (incluyéndonos) creemos leyes que regulan el comportamiento de sus habitantes homologando criterios para convertir leyes en leyes efectivas que puedan comprender actuares volitivos extraños que corrompen a la sociedad, tales como las tratas de personas, crimen organizado, tráfico de drogas, etc., para evitar que la idiosincrasia criolla de nuestro pueblos se contamine.

Los derechos propios del hombre nacen inherentes a cada individuo, son derechos innatos y no son creados por órganos de gobierno, sino que son proporcionados por nuestra naturaleza humana y que se vuelven imprescriptibles manifestándose como: Derecho a la vida y a la integridad física; Derecho a la libertad; Derecho a la igualdad; Derecho a la seguridad; Derecho a la propiedad; Derecho al honor; Derecho al trabajo; sin embargo, dependiendo de la naturaleza de los estados, estos derechos para muchos son inalcanzables y prácticamente se convierte en sueños de libertad.

De esta perspectiva de derechos se puede establecer que los pueblos equiparan una estructura jurídica que regula, controla y sanciona conductas que dañen a la sociedad con la creación de instituciones de orden público, pero no se puede desconocer que la libertad del 
ser humano es un dilema ético, aunque el hombre sepa que existe una ley y que hay normas que rigen la conducta del hombre en sociedad, él sabe que estas normas deben dirigir a la sociedad a la libertad y la paz, por lo que como ser humano él es libre de poder pesar o actuar hasta donde la ley se lo permita, y solo podrá actuar contrario a la ley cuando la protección de la misma se ausente; por ejemplo, los seres humanos pueden ser libre de tener un hijo y hasta el día de hoy en nuestro país no es un delito, sin embargo, una vez fecundado el hijo, los seres humanos no pueden evitar su nacimiento porque hacerlo es contrario a la ley. Finalmente, la titularidad de la conducta para el derecho penal sólo recae en la persona humana, la que se manifiesta en el mundo externo tanto en actos positivos como en omisiones, de manera que pueden existir tipos penales activos y tipos penales omisivos (Código Penal, 2007).

\section{Antecedentes Históricos del delito.}

En principio, el procedimiento penal para los delitos graves era sumario, escrito e inquisitivo; El alcalde del crimen debía hacer personalmente todas las investigaciones del caso hasta establecer la culpabilidad del procesado. En toda acusación se comenzaba por apresar al acusado y para encarcelarlo no se requería ninguna prueba previa. Para obtener su libertad el preso debía demostrar su inocencia. Fácil es comprender que con tal sistema muchos inocentes fueron llevados a la cárcel donde permanecían privados de su libertad, sin prueba ni justificación alguna.

El paso del régimen colonial al Estado-nación fue un largo proceso de seis décadas (1798 1858) que inició a finales del siglo XVIII, cuando la decadencia económica del Imperio español motivó a terratenientes y comerciantes de la provincia del Nicaragua a tomar conciencia que el sistema colonial representaba un freno para su desarrollo. La independencia permitió la libertad de exportación de los productos agrícolas, rompiendo así el monopolio español. Para finales del siglo XVIII e inicios del XIX ya existía en la élite criolla local una cierta conciencia histórica, surgida de la situación de marginalidad en que vivían dentro del sistema colonial, así como de sus propias perspectivas de desarrollo.

En 1821, Nicaragua se separó de España. Desaparecía así el Estado monárquico en la Provincia, el problema era cómo sustituirlo. La urgencia de crear una nueva legitimidad, 
establecer órganos de control y coerción aparecía en medio de una sociedad que durante siglos había desconocido cualquier autonomía y que se había mantenido cohesionada en torno a la legitimidad de la majestad real. La ruptura política acarreó una ruptura social y el desborde de fuerzas hasta entonces mantenidas bajo presión (Mejía Lacayo, 2013).

Después de la independencia, Nicaragua estuvo inmersa en una permanente situación de violencia por las luchas entre las familias dominantes que se disputaban el poder. Particularmente, las élites de León y Granada se enfrentaron en lucha por la hegemonía, siendo esta una de las causas principales del atraso en la conformación de un Estado nacional. Sin embargo, en la última década del período conocido como el de la Anarquía (1849-1858) se organizaron las relaciones entre los grupos oligárquicos.

En 1824, la fundación de la República de Centroamérica introdujo un nuevo elemento de perturbación. Las discusiones y las luchas se centraron principalmente, aunque no exclusivamente, en dos aspectos. Había quienes trataban de articular el nuevo Estado en torno a una modernización de las instituciones opuestas a quienes querían mantener el antiguo orden colonial. Unos abogaban por un Estado Federal fuerte, otros favorecían la autonomía de los diferentes estados, lo que generó disturbios que culminaron con el asesinato del Jefe de Estado, José Zepeda, en 1837, y la separación del Estado Federal al año siguiente.

En Nicaragua actualmente existe una norma regulatoria de delitos y faltas denominada ley 641 "Código Penal de Nicaragua" que castiga las acciones dolosas e imprudentes y las omisiones cometidas por todas las personas que se encuentra dentro de sus fronteras y la misma norma determina las conductas que se pueden eximir al actor de la sanción penal, atenuarlas o agravar la pena (Código Penal, 2007).

Desde cualquier punto de vista la protección de la Constitución está integrada por aquellos instrumentos políticos, económicos y sociales y los de técnica jurídica que limitan el poder y logran que sus titulares se sometan a los lineamientos establecidos en la propia Constitución; con el único fin de garantizar el Estado de Derecho, ya que con estos instrumentos se pretende lograr la marcha armónica, equilibrada y normal de los poderes públicos y en general de todo órgano de autoridad, lo que origina la supremacía constitucional 
que no puede ser quebrantada por ningún Juez de este tan anhelado Estado de derecho, y especial en contra de un procesado.

En Nicaragua no se puede determinar con claridad actualmente de dónde se originan las acciones delictivas, sin embargo, en esta investigación tomamos preceptos universales, como el camino al crimen o INTER CRIMINI que es uno de los elementos que nos lleva a determinar la participación de los acusados en los hechos, la relevancia de la investigación de los orígenes de la acción delictiva de los delincuentes, quizás en un tiempo lejano tendremos una normativa de investigación con unificación de lo antropológico, de la sociología y lo que se conoce en la criminología como génesis del delito.

Ahora bien, existen algunos rasgos y estudios que sirven de apoyo, por ejemplo, lo que se conoce como alineación, observamos, pues, que la sociedad nos alinea para vivir en ella; pero, ¿qué sucede cuando el individuo dentro de la sociedad no está conforme y considera que las normas sociales no tienen el carácter moral para educarlo y se causa una anomia (rechazo al sistema) y determina que su condición en la que se encuentra es producto de la pobreza en que vive, que no consigue trabajo por su bajo nivel intelectual, de por qué el estado no le creó las condiciones que le permitiese adquirir conocimientos básicos, y que la causa de todos sus problemas es la injusticia social y económica, y decir que al haber una mala distribución de riqueza, falta de oportunidades, desempleo, explosión demográfica es, en general, por una mala administración política, provocada por incompetencia, por corrupción de los gobernantes y sea la consecuencia de estos la gran posibilidad de formación de un delincuente?

Los fenómenos cambian y el derecho transforma los fenómenos sociales en leyes positivas para que coexista la sociedad. Sin leyes no existe gobierno. Sin embargo, saber de dónde se originan las acciones delictivas de los delincuentes es compleja debido a los cambios en la sociedad y a la necesidad misma de los pueblos.

En consecuencia, la línea para seguir pasa por mantener que si no es culpable quien no comprende lo ilícito del hecho o quien no es capaz de actuar conforme a esa compresión incurre en error, encaminado entonces a la desviación del conocimiento y volición como base del delito mismo cometido por el infractor adulto. 


\section{Tendencias delictivas en Nicaragua.}

La tasa de criminalidad en Nicaragua ha crecido en los últimos 12 años y las principales víctimas son personas en estado de vulnerabilidad social, dentro de ellas, las mujeres y niñas menores de 13 años. Mientras el mayor índice de homicidios se registra en el Caribe de este país, según un estudio del Programa de las Naciones Unidas para el Desarrollo (PNUD, 2011).

El PNUD (2011), presentó en Managua la monografía "Nicaragua, riesgos, retos y oportunidades" en materia de seguridad, en la que registra una tasa de 14 homicidios por cada 100.000 habitantes en 2009 en todo el país. El estudio, dirigido por el ex subdirector de la Policía Nacional de Nicaragua Francisco Bautista, también señala que los robos con intimidación pasaron de 54 a 194 por 100.000 habitantes entre 1998 y 2009 y la tasa de violación se incrementó de 26 a 34 casos por cada 100.000 habitantes en los últimos 12 años. Además, cada año el $22 \%$ de la población nicaragüense está relacionada a la delincuencia, ya sea como víctima, detenida o familiar, mientras que la atención a los crímenes consume el $10 \%$ del Producto Interno Bruto del país, "El riesgo a ser víctima de un delito en Nicaragua aumentó dos veces en la última década, también aumentó la población detenida y las mujeres

y niñas menores de 13 años son cada vez más víctimas de los crímenes y menos victimarias", advirtió Bautista, al presentar el estudio.

\section{Tabla 1}

Tendencias delictivas de Nicaragua estadísticas del año 2007 al 2010.

\begin{tabular}{lrrr}
\hline Año & Total, de delitos & Tasa de incremento & IDD x 10 mil h \\
\hline 2007 & 4,092 & 3.1 & 245 \\
2008 & 4,305 & 5.2 & 257 \\
2009 & 5,635 & 30.8 & 335 \\
2010 & 5,858 & 3.9 & 347 \\
\hline
\end{tabular}

Fuente: PNUD (2011)

Como podemos observar en la tabla 1 anterior, el 2009 fue el año que experimentó un incremento significativo del delito en el departamento de Rivas. Este aumento impactó 
directamente sobre la población departamental ese año porque significó casi 100 delitos más en la incidencia delictiva (IDD) sobre la población que en el 2008.

Las violaciones, robos en todas sus modalidades y las lesiones son los delitos que más denuncian presentan en las delegaciones municipales y departamentales de la Policía Nacional en Rivas; es decir, los delitos contra la vida, contra la integridad y libertad sexual y contra el patrimonio y el orden socioeconómico.

Durante el período 2007 - 2010, los delitos que se mantuvieron en constante incremento fueron los de la familia contra la vida y contra la libertad, los cuales aumentaron a una tasa promedio de 27.3 y 18.1 por ciento respectivamente. Solamente los delitos contra el patrimonio y los relacionados con estupefacientes experimentaron una tasa negativa del 9.5 y 32.9 por ciento sólo para el 2010. Cabe mencionar, que en los últimos años ya no se dan a conocer datos ni por la policía ni por los operadores del sistema de justicia.

\section{Ilustración 1}

Incidencias delictivas en enero 2019

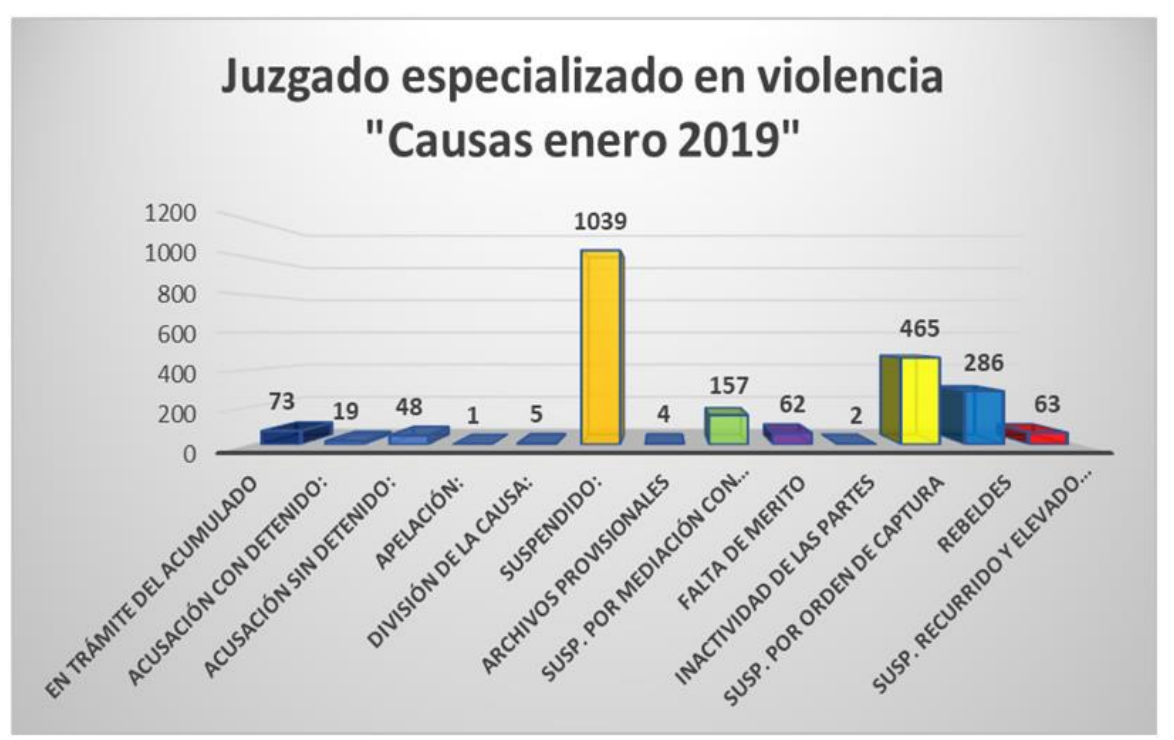

Fuente: Corte Suprema de Justicia (Poder Judicial, 2019)

Debemos de considerar, por lo tanto, que las tendencias delictivas y la criminalidad en nicaragua y sus departamentos fluctúa de acuerdo a las características exógenas y endógenas, y que los índices de la violencia, el delito y la inseguridad ciudadana son, en 
primer lugar, características y responsabilidades de las diferentes instituciones involucradas (generales y especializadas) y sobre todo el estado, y no podemos olvidar, en segundo lugar de los diferentes contextos geográficos en que ocurren o concurren los dos elementos antes señalados (campo y ciudad, población, condición de vulnerabilidad), pues ello brindará características diferentes a la problemática de la inseguridad ciudadana y sus alternativas de respuesta por parte del conjunto social y la prevención del delito.

Condiciones y características de vulnerabilidad sociales, culturales y personales del tipo infractor adulto en la comisión de delitos.

\section{Caracterizaciones geográficas y sociales.}

De acuerdo al planteamiento investigativo, las acciones antijurídicas generadora de delitos y falta no ocurren en forma aislada en los departamentos objetos de estudio, sino que se manifiestan dentro de un fondo situacional complejo de características multidimensionales, transculturización y aquellas propias del entorno circundante, por lo que es necesario entonces profundizar en la situación ambiental, social y económica de los sujetos investigados colaboradores de este estudio, para ayudarnos a identificar algunos de los factores transformadores de la conducta que en este municipio conllevan a la comisión de delitos y faltas.

Para tal efecto, nos apoyaremos en los datos obtenidos por el sistema Nicarao (sistema de Gestión judicial de impulso procesal, que está diseñado para registrar todas las actuaciones de un proceso judicial y mide la gestión diaria del órgano jurisdiccional), que, si bien es cierto, se alimenta de acuerdo al censo de la judicialización de causas de la población delictiva, realizado constantemente, y con algunas proyecciones que nos indican que la tasa anual promedio de crecimiento poblacional delictiva, delitos más frecuentes, datos propios de audiencias, estrategias de defensa material y técnica, los cambios a nivel, sociodemográfico y sobre todo los elementos objetivos y sugestivos de la población delictiva. 


\section{Caracterizaciones geográficas de la acción delictiva.}

En los últimos años en la mayoría de los países de América latina se ha homologado muchas leyes con el propósito de combatir las estructuras transnacionales delictivas y Nicaragua no es la excepción, sin embargo, la realidad jurídica de la aplicación de las leyes en nuestro país nunca va de acorde al estudio intrínseco del individuo infractor de la ley penal ni de su desarrollo social y humano, su origen y su conexión geográfica.

El factor común en las modalidades delictivas se da por sector geográfico en nuestro país y se hace tan evidente que los litigantes de la rama penal logran de manera natural identificar, según la ubicación geográfica, cuál es la comisión de delito. Todo litigante conocedor sabe por ejemplo que el departamento de Rivas por ser una zona fronteriza los delitos comunes son violaciones, robos en todas sus modalidades, delitos contra la vida, contra la integridad y libertad sexual y contra el patrimonio, orden socioeconómico, tráfico de droga en sus distintas modalidades, crimen organizado, tráfico de migrantes, etc.

Según el análisis de este artículo se hace necesario por la creciente incidencia delictiva del departamento de estudio, la necesidad no sólo de conocer los factores humanos del delincuente generador de acciones antijurídicas, sino también la necesidad de localizar los lugares donde se cometen estas acciones criminales, para considerar herramientas concomitantes y crear un perfil geográfico que vincule no solo al delincuente sino también a la víctima como nexo causal. En concreto, los crímenes generados en un lugar determinado generan una importante alarma social, por lo que los medios de comunicación juegan un rol de presión en las autoridades para la prevención delictiva, en este caso los cuerpos policiales. Por ello, los lugares en los que se cometen los delitos son cruciales en la investigación criminal, pues constituyen muchas veces una pista que, analizada científicamente, puede ser fundamental en la resolución de los casos investigados.

3. Condiciones sociales, población y económica del departamento objeto del estudio.

Rivas está catalogado como una de las áreas geográficas más vulnerable para la comisión de delitos propios del crimen organizado, por eso se hace necesario para este estudio, conocer su condiciones sociales, población y economía de sus pobladores, si observamos su 
condiciones geográficas asociadas a la actividad económica, el turismo y una débil capacidad de las instituciones de seguridad y políticas de prevención del delito, ha hecho que las actividades de crimen organizado se desarrollen de manera voraz y se concentra aquí la mayor cantidad de población delictiva del país y de circulación de lavado de bienes y activos, lo que permite el ocultamiento de las actividades criminales del crimen organizado.

La población total del departamento de Rivas asciende a más de 156,323 habitantes compuesto por nativos, turistas, rentistas, residentes, visitantes etc., lo que hace que Rivas sea el departamento con una población densamente habitada y con una diversidad cultural. Similarmente, los grupos poblacionales por sexo tienen casi la misma proporción, los hombres representan el 48.7 por ciento, mientras que las mujeres representan el 51.2 por ciento. Otro detalle interesante es que existe mayor población urbana (67.3\%) que rural $(32.6 \%)$.

Tabla 2

Censo de Población y de Vivienda estadísticas 2017 del departamento de Rivas

\begin{tabular}{lrrrrr}
\hline Municipio & Población & $\%$ & $\begin{array}{c}\text { Orden de } \\
\text { primacía }\end{array}$ & $\begin{array}{c}\text { Superficie } \\
\text { Km2 }\end{array}$ & $\begin{array}{c}\text { Densidad } \\
\text { poblacional }\end{array}$ \\
\hline Rivas & 41,080 & 26.2 & 1 & 280.5 & 146 \\
Tola & 22,012 & 14 & 2 & 476.5 & 46.1 \\
Altagracia & 19,995 & 12.7 & 3 & 211.2 & 94.6 \\
Belén & 16,428 & 10.5 & 4 & 246.2 & 66.7 \\
San Juan del Sur & 14,741 & 9.4 & 5 & 411 & 35.8 \\
Potosí & 11,904 & 7.6 & 6 & 143.5 & 82.9 \\
Moyogalpa & 9,729 & 6.2 & 7 & 65.9 & 147.6 \\
San Jorge & 8,024 & 5.1 & 8 & 24.8 & 323.5 \\
Cárdenas & 6,990 & 4.4 & 9 & 226.6 & 30.8 \\
Buenos Aires & 5,420 & 2.8 & 10 & 75.2 & 72 \\
\hline
\end{tabular}

Fuente: Elaborada por INIDE (2017)

A su vez, la población es eminentemente joven, también, el grupo etario más numeroso está comprendido entre las edades de 10 a 24 años, el cual representa el 33.6 por ciento de los habitantes totales del departamento de Rivas. Un segundo grupo etario más grande es el comprendido entre los 25 y 49 años, quienes representan el 31.6 por ciento de la población total. 
Incidencia de la pobreza: Rivas está catalogado como una de las áreas geográficas de pobreza baja, de acuerdo con el Mapa de la Pobreza en Nicaragua. A nivel departamental, Rivas tiene una incidencia de la pobreza extrema del 26.8 por ciento del total de hogares, lo que indica que solamente esta tasa de hogares tiene un alto nivel de necesidades básicas insatisfecha. A nivel municipal la incidencia de este tipo de pobreza se reduce al 13.5 por ciento de un total de 1,239 hogares.

Esto podría deberse al hecho de que este departamento es uno de los más productivos a nivel nacional: desde hace ya varios años, se viene explotando las bellezas geográficas de este departamento al punto de convertirse en uno de los principales destinos turísticos del país. Aunque es difícil conocer con exactitud los datos oficiales sobre la actividad turística en Rivas, se reconoce que en los últimos años ha habido un auge del turismo. Por ejemplo, no se conoce cuánto de los turistas que ingresan al país, viajan a Rivas como destino turístico. Asimismo, no existen datos desagregados sobre el gasto del total de turistas a nivel departamental y municipal, entre otros. Sin embargo, algunos datos proporcionados de manera irregular pueden darnos una idea del decrecimiento de la actividad turística en Rivas por las últimas situaciones sociopolíticas.

\section{Ilustración 2}

Informe de procesado por la ley 779

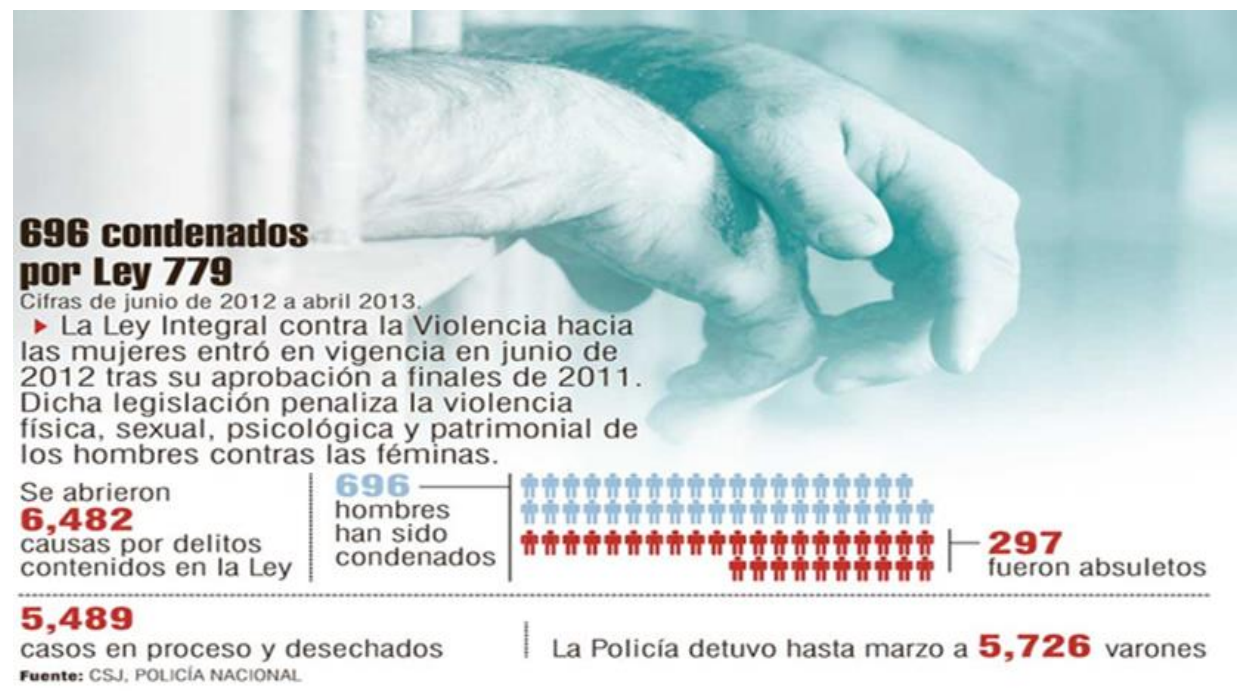

Fuente: Policía Nacional (2013) 
Ocupados y desocupados: Si tomamos uno de los 10 municipios del departamento de Rivas, observamos que la población económicamente activa (PEA) del municipio de Rivas asciende a 15,783, que representan el 38.4 por ciento de la población total. De ellos, el 64 por ciento son hombres y el 35.9 son mujeres. Un dato interesante nos muestra que la mayoría de la PEA está ocupada en trabajos permanentes, mientras que una minoría en trabajos temporales, lo cual podría indicar que las tasas de ocupación laboral en este municipio son altas.

Según los datos, el porcentaje de hombres ocupados con trabajo permanente es del 63.9 por ciento, mientras que en las mujeres es del 77.7 por ciento. Otro dato considerable es que el porcentaje de hombres trabajando en empleos temporales asciende al 32.1 con relación a la población total masculina económicamente activa, el de las mujeres es de apenas el 17.3 por ciento. Sin embargo, en la actualidad en el departamento de Rivas con la caída del sector turístico, se han perdido una gran cantidad de empleos creando zozobra y migración laboral.

\section{Educación.}

Rivas es uno de los pocos municipios que presentan bajas tasas de analfabetismo: 11.3 y 10.1 en el caso de los hombres y las mujeres en general. Estas tasan bajan aun cuando se desagrega la estadística y agrupamos en forma etaria a ambos sexos; en este caso el analfabetismo es

del 7.1 para hombres comprendidos entre las edades de 14 y 29 años. En el caso de las mujeres la tasa para ese mismo grupo de edad disminuyó a 4.4 por ciento.

De acuerdo con el Índice del Estado Educativo Municipal (IEEM), elaborado por el Ministerio de Educación (MINED), Rivas está clasificado como un "municipio bueno" en materia educativa. Esto significa que los índices de asistencia escolar son relativamente altos: 55.4 para prescolar, 85.4 para primaria y 73.2 para secundaria, por lo que existen bajos niveles de inasistencia preescolar. De acuerdo con las autoridades de educación en esta localidad, esto se debe a que existe una básica infraestructura escolar y a los niveles de ocupación laboral de los padres de familia. En general, el grado de escolaridad del 10 por ciento de la población total de Rivas tiene al menos 11 grados de escolaridad, es decir, con estudios superiores. 
Características que propician la vulnerabilidad por la posición geográfica ante la presencia del crimen organizado.

Según los últimos resultados de investigación disponible en internet del IEEPP (2012) (aclaro que es difícil el acceso a la información pública) las principales actividades de crimen organizado que se concentran en el departamento de Rivas son: Transporte Ilegal de Estupefacientes, Psicotrópicos y Otras Sustancias Controladas, Traslado de Estupefacientes, Psicotrópicos y Otras Sustancias Controladas, Tráfico Ilegal de Estupefacientes, Psicotrópicos y Otras Sustancias Controladas, Posesión de Estupefacientes, Psicotrópicos y Otras Sustancias Controladas, Tráfico de Migrante ilegales, tráfico de armas y contrabando de mercaderías, crimen organizado, violencia psicológica, patrimonial, violaciones, femicidios, homicidios.

Es importante señalar que, según estadísticas del sistema Nicarao en el departamento de Rivas, en el año 2018 se ventilaron 2,244 causas comunes de relevancia, en el año 2019 se ventilaron 1,833 comunes y en el año 2020 se ventilaron 2,038 comunes, cabe resaltar que estas causas fueron conocidas por el Juez de distrito penal de Juicio por ser las misma considerada según su tipificación como delitos graves.

La Actividad turística como fenómeno transformador de la acción antijurídica.

El desarrollo turístico en el departamento de Rivas es uno de los factores de riesgo autóctono más común generador de acciones antijurídicas y debemos ser cauteloso en la descripción de aquellas características que generan acciones delictivas por lo que para este estudio debemos separar el turismo local y el turismo extranjero.

Si bien las estadísticas actuales reflejan cifras bajas de turistas por razones del problema sociopolítico de abril 2018 que hasta la fecha no se ha superado y la pandemia causada por el Covid-2019, sin embargo las víctimas de robos y hurtos se han hecho evidente por las condiciones económicas alarmante de la población, ahora bien porque la mayoría de 
los extranjeros no se presentan a denunciar el hecho y, además, porque cuando el valor del bien material sustraído es menor a dos salarios mínimos del sector industrial, el hecho no es considerado delito, sino una falta penal que puede ser solventada por medio de la mediación como manifestación del principio de oportunidad establecido en el Código Procesal Penal.

Los extranjeros han dejado huellas en el departamento de Rivas, y sus acciones alteran los índices delictivos en el departamento, sobre todo por la relevancia de sus acciones delictivas; los extranjeros cuando son consideradas víctimas los delitos cometidos en contra de ellos, son delitos de robo, hurto, estafa y cuando ellos son los autores de acciones antijuridicas los delitos son más orientado a la violación, asesinato, femicidio, estafas, que según lo dicho por el jefe policía estos últimos se denominan como delincuentes flotantes, la razón es porque son cometidos por personas foráneas, que por sus puestos al momento de medir índices por algunas instituciones o sectores no se determina si las acciones delictivas fueron cometidas por un nacional o extranjeros.

El caso más relevante relacionado al turismo en el departamento de Rivas es el caso “Doris Jiménez, quien fue asesinada el martes 21 de noviembre de 2006, entre las 11:45 a.m. y la 1:00 p.m. en San Juan del Sur, Nicaragua. Su cuerpo fue encontrado alrededor de las 2:00 p.m. dentro de su tienda ropa. Fue atada, estrangulada y asfixiada, según asesinada por Eric Volz”. Lo antes dicho impone que los estudios y estadísticas arrojen cierta comisión de delitos de parte de extranjeros.

Ilustración 3

Juicio Eric Volz
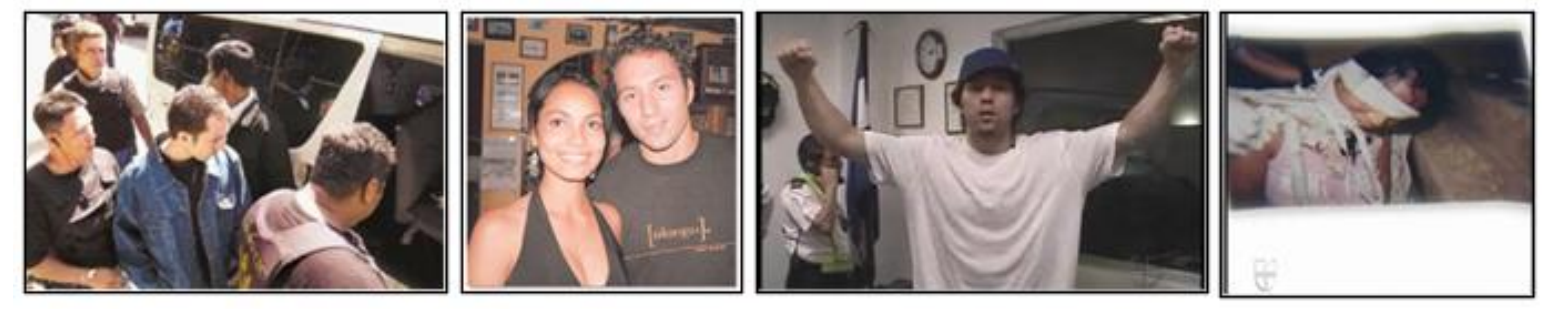

Fuente: Gringo Nightmare por Volz (2010) 
Mora., R., M., E.

Tras varios días de misterio, este martes se dio a conocer por fin la fecha de reprogramación del juicio en el que se conocerá si condenan o no al mexicanonorteamericano Eric Stanley Volz, por el atroz crimen de su novia, Doris Ivania Jiménez Alvarado. La fecha de reprogramación fue fijada para las nueve de la mañana del 14 de febrero, según lo dio a conocer la juez de Distrito Penal de Juicio de Rivas, Ivette Toruño Blanco, en un auto que dictó a las 2:30 de la tarde del martes, en los juzgados de Rivas. En un inicio el juicio estaba programado para el 26 de enero, pero se canceló debido a que el juez de audiencia, Edward Peter Palma, pasó el expediente al juez de Distrito de Juicio un día antes de la fecha establecida.

Factores comunes y autóctonos que potencian la acción delictiva en Rivas el departamento de Rivas.

Para entender una determinación de un hecho antijurídico debe tener muy en cuenta la naturaleza de la infracción, las circunstancias propias del hecho y el impacto social del mismo; es decir, la complejidad del hecho como resultante de una ruptura social que, a través de entrevistas de campos y grupos focales, podemos argumentar para identificar dos tipos de factores de riesgos: comunes del entorno geográfico (presencia del crimen organizado) y autóctonos.

Factor común la Presencia del crimen organizado.

Según la ley 735 se considera crimen organizado: todo grupo delictivo organizado o banda nacional o internacional estructurada, de dos o más personas, que exista durante cierto tiempo y que actúe concertadamente con la finalidad de obtener directa o indirectamente, un beneficio económico o de cualquier índole, con el propósito de cometer uno o más delitos graves establecidos en la Ley; observemos que las condiciones geográficas del departamento de Rivas es propiciantes de actividades que se concentren en el borde fronterizo y se proyecten a la ciudad de Rivas por conducto de la Carretera Panamericana y, además, el tejido social (Poder Judicial, 2017).

El grado de riesgo o peligro que ocasiona el crimen organizado en una estructura social, sobre todo fronteriza transforma en su totalidad la conducta delictiva de los habitantes, 
y las medidas necesarias para prevenir los delitos pudiendo adoptar mecanismos únicos para el departamento con el fin único de crear políticas de estados fuertes como medida de prevención.

El Tráfico de migrantes detonante de la delincuencia organizada y la vulneración ciudadana.

Uno de los casos que Nicaragua que es sintomático de los antes dicho, fue la afluencia de migrantes cubanos y de otras nacionalidades se apostaron en la frontera sur en noviembre del 2015, ofreciendo dinero para cursar de manera irregular el territorio nacional, y muchos de los pobladores del departamento de Rivas se vieron inmersos en esta actividad delictiva fuese de manera dolosa o de manera imprudencial.

Dentro de los casos más sonados fue el de la profesora Nilamar Mora que se llevó una migrante irregular de nacionalidad del Congo y fue capturada en el norte del país. Dicha historia hizo que la población cambiara su imagen a esta situación que estaba alterando el entorno social del país. En esa fecha el titular del periódico "policía señala a maestra de tráfico de migrantes, fue condenada y luego liberada por la presión social (La Prensa, 2016). Es de resaltar que, la migración irregular fue la panacea delictiva durante el 2017, 2018 y 2019.

Cabe destacar que durante la persecución del estado a todos los ciudadanos que cometían este ilícito, se violentaron muchos derecho humanos y constitucionales y aunque la normativa regulatorio del tráfico de migrantes que se encontraba en el artículo 318 del Código Penal, fue reformar por la ley de Trata de personas en su artículo 63 que reforma el artículo 318 Tráfico de migrantes y, por consiguiente, define: "Quien con fines de migración ilegal, facilite, promueva o favorezca por cualquier medio la entrada salida o permanencia de una persona del territorio nacional será penado de cinco a ocho años de prisión y de quinientos a mil días multas, con igual pena se sancionará al que:

1. Contrate, traslade, transporte oculte o alberque personas con fines de migración ilegal; 
2. Habilite a una persona que no sea nacional o residente para permanecer en el territorio nacional sin haber cumplido los requisitos para permanecer legalmente en el mismo recurriendo a medios ilegales;

3. Elabore, confeccione, facilite, suministre o posea documentos de viajes o de identidad falsos con el propósito de hacer posible el tráfico ilícito de migrantes, así como quien facilite o porte documentos de identidad auténticos que pertenezca a otra persona con los mismos fines.

Durante estos años la persecución de la criminalidad del tráfico de migrante fue contundente, sin embargo, debo reconocer que es estado la satanizo, creando un estado "político- criminal” convirtió la judicialización de la migración en una prioridad estatal lo que complicó el derecho a la defensa, creando acciones que se contraponían al proceso mismo reformado y por qué no decirlo violentando el debido proceso.

En esta investigación de la cual logré defender a más de treinta acusados por este delito de tráfico de migrantes, la óptica de la prevención del delito, el estado la satanizó agravando las sanciones a los que infringían la ley para este tipo penal de tráfico de migrantes y olvidó lo esencial que era identificar cuáles son los factores biopsicosociales y ambientales que más inciden en el incremento de la criminalidad, para poder determinar si tiene la presencia de la criminalidad organizada, tomar muestras si el procedimiento es el correcto para el Juzgamiento de estos delitos y conocer las características del problema en Nicaragua qué hacer, cómo intervenir y cómo abordar este fenómeno.

\section{3.- MÉTODO}

Existe relación entre la vulnerabilidad social (educativa, económica) del infractor adulto y la comisión de delitos graves en el departamento de Rivas, sus condiciones de hacinamiento carcelario que se suscitó entre el año dos mil quince y el año dos mil veinte, en todo el país y sobre todo en el departamento de Rivas, y que fueran expuestas por distinto organismos, medio, familiares y los distintos reos participantes de este estudio, son motivo de vulnerabilidad social, y el detonante de la criminalidad en el que se encuentran los distintos grupos de personas que componen la población del departamento de Rivas y sus municipios. 
El estudio tiene un diseño descriptivo y observacional. Se realizaron entrevistas focalizadas con los investigados, acusados y los miembros de la familia de los procesados y se trabajó con información de los expedientes judiciales.

Los datos recogidos se tomaron de muestra sobre personas que tienen causas penales en el Juzgado de Distrito Penal de Rivas en el año dos mil catorce hasta el año dos mil dieciocho, Además se tomaron algunos casos sonados en delitos especiales Erik Volz, casos que fueron candidatos consecutivos por la gran relevancia Social. En el mismo orden de ideas, todos los participantes han sido muestreados en los centros de detención, además, se practicaron cuestionarios, se tomaron datos sociales conforme a los recortes de los diarios de circulación nacional y se aplicaron test psicológicos a los participantes, además, se revisaron los índices delictivos del informe policial correspondiente a los años de estudios.

Por otro lado, el procedimiento utilizado en esta investigación posee elementos cualitativos de descripción de hechos y acontecimientos que se fueron suscitando a lo largo del proceso investigativo tales como expediente, documentos, estudios de casos, entrevistas información tercerizadas etc. Finalmente, la composición de la muestra por edad cronológica según la muestra de estudios de cien causas judicializada en el departamento de Rivas en delitos graves comprendida entre el 2015- hasta el 2018 aplicando la Escala de conductas antisociales y delictivas (Formiga \& Gouveia, 2003). Cabe resaltar que en la mayoría fui defensa técnica de ellos, en algunos casos como abogado privado y otros como abogado de oficio.

\section{4.- CONCLUSIONES}

El presente estudio se realizó en el marco de un crecimiento del desarrollo del conocimiento científico-jurídico de los involucrados en la administración de la justicia penal, con la premisa de establecer factores humanos y sociales del individuo en la comisión de delitos y faltas, contándose con las posibilidades indispensables del acceso a la información (muy difícil). Entre las fortalezas del estudio puede mencionarse que se realizó sobre un número importante de población, durante más de cuatro años, lo que permitió obtener una muestra significativa de sujetos y grupos receptores. 
A su vez, y por lo expuesto precedentemente, el tamaño de la muestra específicamente se debió dejar de lado consideraciones más profundas y personales, así, como, por ejemplo, la realización de mayor cantidad de entrevistas sobre el mismo grupo receptor. En este sentido cabe mencionar que, como lo producido como información es parte de los datos judiciales y de los expedientes de causas judicializadas en el departamento de Rivas, para decidir sobre el otorgamiento de una medida de morigeración de la condena o salidas anticipadas, el tiempo de investigación no podía extenderse en demasiados días, para cada caso en particular.

La intención que guio esta investigación fue la de caracterizar en el contexto más próximo compuesto por posibilidades y problemas sociales y ambientales que enfrentarán los sujetos infractores de las leyes penales en el departamento de Rivas, ante los criterios de judicialización, las inobservancias de derechos fundamentales, constitucionales y de procedimientos utilizados por los jueces penales administradores de justicia, luego de un período de detención, realizando el análisis respetando las dimensiones clásicas sobre las que los Trabajadores del sistema judicial en función de la pericial a la que son llamados a responder. Dicha caracterización, que permite definir cierta condición de vulnerabilidad, tomando como referencia el cumplimiento de garantías constitucionales, sanción y condena y la reinserción social del infractor penal de la ley nicaragüense.

Las condiciones sociales que son el marco del desarrollo social de este país y el núcleo fundamental de la familia, según esta investigación, aparecen entonces como protagonistas del destino de los acusados y procesados y en los delitos sexuales como generadores de violencia. Si el paternalismo del estado social menguaba las posibilidades de transformar al ciudadano en un consumidor de delincuencia, la situación del condenado a la reinserción social no garantiza la exclusión del acusado si su entorno no ha sufrido ningún cambio, a su vez este individuo que fue objeto de estudio emerge en un nuevo dilema de cuestión social signada por la fractura, la desintegración del trabajo como criterio de solidaridad y una vulnerabilidad más amenazante por su capacidad de pernear a casi toda la estructura social, cualquiera que sea la calificación que se posea. 
Sostengo que la problemática arrojada por este estudio que buscaba auscultar las condiciones que facilitaren o propicien las transformaciones jurídicas y humanas en las formas de judicialización, sanción y reinserción social del infractor de la conducta antijuridica, no está solamente referenciada con condiciones sociales, históricas, económicas del departamento de Rivas y sus municipios de manera estructural, sino y especialmente, con la configuración que estas condiciones tienen o adquieren para cada grupo en particular sobre todo cuando se exponen derecho y los mismo se convierten en violaciones a derechos humanos, para cada familia, cada sujeto involucrado. Más allá de las dificultades prácticas y políticas quisiera poner el énfasis en un problema de mayor importancia para la vida intelectual y política del departamento de Rivas: es la necesidad de alejarse de un enfoque determinista, y comenzar a ver la prevención de las acciones delictivas con políticas de empleo, crecimiento personal, deporte, mayor educación, mayor asistencia social, etc. en última instancia las conductas personales y colectivas.

Puede inferirse que, las condiciones de vulnerabilidad que enfrenta la población penal muestra de esta investigación una vez acontecida su liberación por medio de cualquier mecanismo del sistema de vigilancia penitenciaria, aparecen fuertemente relacionadas con factores estructurales, políticos y mantendrán estrecha relación con la condición previa a la detención. O sea, dichos sujetos no han contado con el apoyo de su familia; sin embargo, es real que existe un importante porcentaje de reincidencias, una importante cantidad de personas y grupos familiares que finalmente fracasan, y vuelven a las condiciones de detención.

En este punto aparece como necesario entonces, y a la luz de los resultados obtenidos en la investigación, no sobredimensionar el rol de las familias o los grupos receptores por el abandono temprano durante la condena o el proceso, al momento de considerar las condiciones de vulnerabilidad, y a su vez, por ello justamente, obliga a mirar más allá del interior del grupo, obliga a observar las condiciones sociales generadoras de sujetos que cometen delitos o reinciden en el mismo.

Lo que se observa como resultado final es que en Nicaragua y en especial en el departamento de Rivas (el departamento muestra de esta investigación) que las condiciones 
ambientales a que se mira expuesta la población ponen en evidencia que la criminalidad emerge de una muy compleja conjunción de factores. Uno, la exclusión social que habría producido profundos procesos de fragmentación social, particularmente nocivos al interior de los enclaves urbanos y rurales de sectores de bajos ingresos. Otro, se vincularía al funcionamiento de sectores del Estado partidarizado. Lo que creemos es que estos realimentan los ciclos de violencia, no solamente porque estigmatizan y reprimen a los sectores subordinados; además, por que las instituciones públicas se habrían degradado a atender a un grupo de afinidad partidaria, contribuyendo al proceso de dos maneras: indirectamente, al perder su capacidad de encarnar los consensos sociales habrían dificultado la vigencia de acuerdos sociales mínimos que regulen la convivencia, lo que de alguna forma fomenta la violencia; a tal punto de funcionar de manera similar a una organización mafiosa que produce violencia delictiva ella misma.

A modo de síntesis es importante destacar que:

- Los acusados y procesados por las leyes penales nicaragüenses y sus familias involucradas en el estudio presentaron características, que, desde lo constitutivo, permita ubicarlos en un nicho de "delincuentes" o como "posibles reincidentes".

- Se puede hacer mención que los acusados provienen de familias socialmente ubicadas en condición de vulnerabilidad o pobreza extrema, por factores estructurales que impactaron negativamente en su cotidianeidad (condición socio política de abril 2018), y que por ello abandonaron a uno de sus miembros luego de la reclusión carcelaria.

- Se detectó un importante número de familias o individuos considerados en situación de desafiliación o marginalidad absoluta.

- Que las dimensiones tradicionalmente utilizadas para el análisis de estadísticas de condiciones carcelarias no aportan por sí demasiado al esclarecimiento del fenómeno de la comisión del delito y las reincidencias.

- El aporte del Trabajo social en el análisis de la problemática, en los procesos penales y por sobre todo al momento de pensar políticas que aborden la tarea de la prevención, se halla vinculado con la explicación de los mecanismos a través de los cuales, y el modo en que, lo estructural se inserta en cada historia particular. 
- El Trabajo Social en función pericial debe aportar al conocimiento desde esta perspectiva. Los profesionales de la Psicología, los de la Psiquiatría, los de la Criminalística aportaran desde sus propias disciplinas, no descuidando la perspectiva totalizadora indispensable.

- El abordaje entonces debe ser social, económico, cultural y educativo. Debe prevenir, no con más punición, sino con más inclusión e igualdad.

\section{5.- RECOMENDACIONES}

Que se cree un mecanismo multidisciplinario para evitar la incidencia delictiva en el departamento Rivas y sus municipios, sobre todo que se revisen las acciones más frecuente generadora de delitos, un avance importante sería que se restablezca la información anual de la actividad delictiva, es menester que esté de manera pública y con fácil acceso, que se respeten los derechos de los acusados y sus garantías mínimas

La investigación duró cuatro años y cabe resaltar que las autoridades utilizan los mismos métodos de prevención del delito en ese periodo, como lo es penalizar con más fuerzas las conductas infractoras, solo en el año 2020 se crearon más de siete leyes que penalizan a los infractores hasta con cadena perpetua por lo que hago las siguientes recomendaciones.

Que, A pesar de la presencia del crimen organizado en el Departamento de Rivas y sus municipios, la violencia originada en la delincuencia transnacional es prácticamente invisible, porque nicaragua solo es ocupada por los delitos de peligro abstracto y de mera actividad como zona transitoria, por lo que podemos decir que la población de este departamento se ve más afectada por la alta incidencia de delitos comunes. Y es ahí donde debemos buscar soluciones.

1. Revisar los índices de los delitos de mayor crecimiento y sobre todo que alteren el entorno social, de acuerdo con el análisis que se ha hecho en años anteriores por los distintos organismo estatales y no gubernamentales. A su vez revisar los índices de pobreza, educación etc. 
2. Presenta indicadores socioeconómicos satisfactorios y preventivos de otros municipios del resto del país para que las autoridades como los líderes comunales, estudiantes y comerciantes, identifican que el este problema incide directamente en la inseguridad elevando sus índices en forma negativa en el departamento de Rivas.

3. Mantener un estudio constante sobre los fenómenos que alteren el entorno ambiental, sobre todo con los rubros más vulnerables que inciden en la inseguridad.

4. Constatar las bases de dato del sistema Nicarao (sistema de consulta de causas judiciales, casos, juicios, audiencias), con la policía y el Ministerio Público para revisar la efectividad de la ley, la judicialización de las causas y el cumplimiento de las sanciones para poder revisar si verdaderamente se puede dar por certero cual es la incidencia delictiva en el departamento de Rivas, los delitos más comunes y frecuentes y que tipo de población delictiva cuenta el departamento de Rivas.

5. Identificar estructuras y presencia de acciones del crimen organizado, fortalecer la respuesta institucional y de las instituciones de prevención del delito como la Policía Nacional ha dado mayor prioridad a los delitos de mayor impacto social, como las muertes violentas, violaciones, narcotráfico y otros; mientras que ha descuidado la atención a los delitos de mayor frecuencia como los robos en todas sus modalidades. Este segundo tipo de delitos son los que más afectan a la población y generan en la misma una mayor percepción de desinterés por parte de las autoridades policiales.

6. Dar una atención pública diferenciada al problema de la inseguridad en Rivas. Esto implica que debe formularse una política pública local de seguridad, la cual debe ser construida con la participación de todos los actores sociales, económicos, institucionales y de la sociedad civil representada en Rivas. El objetivo para seguir en esta política pública es reducir al mínimo la incidencia del delito en el municipio de Rivas y, para esto, debe integrar elementos de prevención y combate al delito. Sin embargo, debemos destacar aquí que el componente de prevención debe ser el más importante, sus actividades dentro de los planes.

7. Para iniciar esto, el gobierno central debe coordinar con los gobiernos locales, y se debe tomar la iniciativa e impulsar acciones de apoyo con la cooperación de organismo locales e internacionales y también coordinar con fondos propios, un proceso de diálogo, y discusión para que se consense un objetivo público a perseguir 
en el caso de los factores creadores de violencia y acciones antijurídicas, Por ejemplo, el objetivo público podría ser el de incrementar los niveles de seguridad ciudadana atacando los factores de riesgos identificados y la priorización a los problemas más sentidos por la población.

8. Proporcionar los fondos necesarios con los que se puedan financiar las actividades de prevención pueden ser obtenido de todo el dinero ocupado por el mismo crimen organizado, por ende, deben, del gobierno central debe poner en práctica lo establecido en la ley 735 (ley de crimen organizado) pueden provenir incluso del dinero en efectivo que se le incauta al crimen organizado. Rivas es la segunda ciudad donde más dinero se le ha incautado a elementos del narcotráfico, después de Bluefields. La falta de implementación de la Ley 735 o Ley contra el crimen organizado, brinda una oportunidad para que parte de ese dinero sea demandado por las autoridades edilicias y destinado a programas locales de seguridad ciudadana. Esto es más práctico y beneficioso, en vez que el dinero sea destinado a pensiones de retiro de altos funcionarios judiciales.

9. Establecer los mecanismos de atención a estos grupos focales está diferenciada al poder incluir un elemento único contra la delincuencia contra la delincuencia organizada. Para el caso de Rivas, es necesario Promover políticas de prevención de los delitos que trastocan a la tranquilidad social de los ciudadanos, por lo que queremos llamar la atención en este punto y valoramos urgente que las instituciones involucradas en la prevención de delito promuevan junto con otros actores políticas de prevención de los delitos, En este sentido, se pueden crear tres niveles de prevención: 1-. Prevención temprana, orientada a identificar las causas de las violaciones; Prevención urgente, para mitigar los efectos de la violación; y 3-. Seguimiento, busca garantizar que la violación no se repita. Se pueden crear mecanismos de denuncia anónima, por ejemplo, vía Internet, crear fortalecer campañas educativas de educación sexual y, además, educar para la prevención a nivel individual, dando a conocer el perfil del violador y las condiciones más comunes para que este delito se consuma. 
10. Sería de suma importancia que se pudiese crear condiciones para que el departamento de Rivas tuviese su propio sistema carcelario penitenciario para poder erradicar el hacinamiento, con el que vive la población penal del departamento.

11. Dado las características del departamento, se sugiere crear una institución especializada para tratar los asuntos de los extranjeros visitantes y residentes del departamento de Rivas, y así establecer algún mecanismo de protección recíproca de los extranjeros y los nacionales.

12. Aunque suena utópico fortalecer las políticas existentes en el departamento para mantener a los jóvenes alejados de la droga y los vicios y por ende de la delincuencia organizada.

13. Un aspecto para resaltar y que se debe fortalecer es que a través de las estructuras existente de la policía y los ministerios gubernamentales aún la población mantiene algún grado de temor y respeto y se ha logrado evitar que se creen pandillas delincuenciales con estructuras de alta peligrosidad, con esto dejo claro que esta investigación arrojó que la estructura del crimen organizado es externa y que solo operan el país de manera transitoria y no permanente.

14. Que se le preste atención a los acusados durante el proceso como lo es la ayuda psicológica para lograr crear empatía con la víctima y la sociedad y por ende una adecuación real del proceso de reinserción social.

\section{REFERENCIAS}

Código Penal. (Noviembre de 2007). Código Penal de la republica de Nicaragua, Ley Núm. 641.

Código Procesal Penal de Nicaragua. (2001). Ley Núm. 406, Aprobada el 13 de noviembre del 2001.

Formiga, N., \& Gouveia, V. (2003). Adaptação e validação da escala de condutas anti-sociais e delitivas ao contexto brasileiro. Psico, 34(2), 367-388.

IEEP. (2012). Diagnóstico de la seguridad ciudadana en Rivas. Managua. Obtenido de https://www.ieepp.org

INIDE. (2017). Informe de Censo de Población y de Vivienda estadísticas 2017 del departamento de Rivas.

La Prensa. (22 de Agosto de 2016). Policía señala a maestra de tráfico de migrantes. Obtenido de https://www.laprensa.com.ni/2016/08/22/nacionales/2087610-presentan-comocriminal-a-profesora-que-se-solidarizo-con-migrantes

Llobet Rodríguez, J. (2002). Derechos Humanos en la Justicia Penal Juveni. Revista Espiga, $3(5)$. 
Martínez Peláez, S. (2020). La Patria del Criollo. Guatemala: editorial Piedrasanta.

Mejía Lacayo, J. (2013). Cuadernos del Magisterio.

PNUD. (2011). Seguridad Ciudadana 1998 - 2010. Nicaragua: Riesgos, Retos y Oportunidades. Perspectiva Nacional, Programa de las Naciones Unidas para el Desarrollo (PNUD.

Poder Judicial. (26 de Septiembre de 2017). Ley de prevención, investigación y persecución del crimen organizado y de la administración de los bienes incautados, decomisados y abandonados. Ley Num.735. Obtenido de https://www.poderjudicial.gob.ni/pjupload/comjib/Ley735.pdf

Poder Judicial. (2019). Incidencias delictivas en enero 2019. Rivas. Obtenido de www.consultascausas.poderjudicial.gob.ni

Policía Nacional. (Abril de 2013). Informe de procesado por la ley 779. Nicaragua. Obtenido de www.policia.gob.ni

Policía Nacional. (2018). Libro Blancodelincuencia. Obtenido de www.policia.gob.ni

Ramos Ojeda, D., \& Busso, G. (2001). ulnerabilidad social: nociones e implicancias de políticas para Latinoamérica a inicios del siglo XXI.

Romero, X. G. (2017). Política criminal en materia de prevención del delito de Vicente Fox a Felipe Calderón. Revista de investigación en Criminología y Consultoría Jurídica, 21, 281-299.

Santa Biblia. (1960). Gálatas 5:13. Reyna Valera.

Volz, E. (27 de Abril de 2010). Gringo Nightmare: A Young American Framed for Murder in Nicaragua (1er edición ed.). St. Martin's Press. 